\title{
A STUDY OF ULTRASOUND-GUIDED FINE NEEDLE ASPIRATION CYTOLOGY IN VARIOUS INTRA- ABDOMINAL AND PELVIC LUMPS WITH HISTOPATHOLOGICAL CORRELATION
}

\author{
Neetu Purwar', Anita Omhare2, Swapnil Gupta ${ }^{3}$, Lubna Khan', Prem Kumar Singh ${ }^{5}$ \\ ${ }_{1}^{1}$ Lecturer, Department of Pathology, GSVM Medical College, Kanpur. \\ ${ }^{2}$ Lecturer, Department of Pathology, GSVM Medical College, Kanpur. \\ ${ }^{3}$ Lecturer, Department of Pathology, GSVM Medical College, Kanpur. \\ ${ }_{4}^{4}$ Associate Professor, Department of Pathology, GSVM Medical College, Kanpur. \\ ${ }^{5}$ Ex-Professor, Department of Pathology, GSVM Medical College, Kanpur.
}

\begin{abstract}
BACKGROUND

In surgical practice evaluation of deep, abdomino-pelvic masses or focal lesions involving abdominal sites is often difficult and challenging. Distinction between malignant and non-malignant lesions and particularly inflammatory lesions is vital for patient management. It is mandatory to make a documentary evidence of the nature of the lesion before the institution of therapy and for the prognosis. Nowadays, FNAC is a very good alternative for surgical procedures like diagnostic laparotomy.

Aims and Objectives- To study the cytomorphological features, age and sex distribution of intra-abdominal lesions; to categorise them as inflammatory, benign and malignant lesions with histopathological correlation; and to evaluate the sensitivity, specificity and diagnostic accuracy.
\end{abstract}

\section{MATERIALS AND METHODS}

It is a descriptive type of study that included 94 patients with clinically or sonologically diagnosed abdomino-pelvic masses. FNAC was performed under US guidance. The aspirates were smeared into a minimum of 2 slides and they were routinely stained with $\mathrm{H}$ and E, MGG stain.

\section{RESULTS}

In this study, 94 cases of intra-abdominal lumps were subjected to USG guided FNAC. Out of 94 cases there were 68 (72.4\%) malignant, $10(10.6 \%)$ benign, 11 (11.7\%) inflammatory and 05 (5.3\%) unsatisfactory smears. In our study, liver and the gall bladder were the most common sites. Adenocarcinomas and hepatocellular carcinomas were the most common malignant lesions. This study showed $91.4 \%$ sensitivity, $100 \%$ specificity, $100 \%$ positive predictive value, $83.3 \%$ negative predictive value and diagnostic accuracy of $94 \%$.

\section{CONCLUSION}

Intra-abdominal FNAC is widely accepted as a simple, economical and a safe OPD procedure in the presence of expert cytopathologist with high sensitivity, specificity and diagnostic accuracy, and it can be used as important diagnostic tool for a preoperative diagnosis and management of intra-abdominal lesions.

\section{KEYWORDS}

FNAC, USG, Intra-abdominal.

HOW TO CITE THIS ARTICLE: Purwar N, Omhare A, Gupta S, et al. A study of ultrasound-guided fine needle aspiration cytology in various intra-abdominal and pelvic lumps with histopathological correlation. J. Evolution Med. Dent. Sci. 2018;7(06):750-754, DOI: $10.14260 /$ jemds/2018/170

\section{BACKGROUND}

Ultrasonography guided Fine Needle Aspiration Cytology (FNAC) is currently the most favoured and increasingly used pre-operative diagnostic procedure in various deep seated neoplastic and non-neoplastic mass lesions.

Most of the intra-abdominal masses are non-palpable and even if they are palpable the idea of their size and shape and the extent of the lesion is not possible. Use of imaging modalities like fluoroscopy, CT and USG helps in localisation of lesions and also improved adequacy of sample. ${ }^{1}$

'Financial or Other Competing Interest': None.

Submission 10-09-2017, Peer Review 20-01-2018,

Acceptance 27-01-2018, Published 05-02-2018.

Corresponding Author:

Neetu Purwar,

\#35/New Type 4,

GSVM Medical College,

Kanpur-208002, U. P.

E-mail: neetu.purwar@gmail.com

DOI: $10.14260 /$ jemds $/ 2018 / 170$

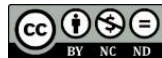

Ultrasound guided FNAC is a common and widely accepted as a safe diagnostic procedure in which any structure visualised can be reached quickly and precisely by a fine needle and it is substitute for surgical procedures like diagnostic laparotomy.2 ${ }^{2}$

FNAC is a highly sensitive, highly specific, accurate and a cost effective diagnostic procedure as shown in most studies with a negligible complication rate.3,4,5,6 However, an absolute contraindication is uncorrectable severe coagulopathy. ${ }^{7}$

Liver is an abdominal organ for which percutaneous FNA is most frequently asked, as liver is involved by many nonneoplastic and neoplastic diseases. Evaluation and management of hepatic lesions is a common clinical problem and their appropriate clinical management depends on accurate diagnosis.

Aims and objectives of our study were to find the incidence of various intra-abdominal lumps with cytomorphological features, age and sex distribution with cytological and histological correlation and to establish the accuracy of USG guided FNAC. 


\section{MATERIALS AND METHODS}

This study is a descriptive type of study, carried out on 94 patients presented with intra-abdominal and pelvic lumps attending the outpatient department as well as admitted in Medicine, Surgery and Gynaecology and Paediatric wards of LLR and associated hospitals, Kanpur. The study was carried out from January 2011 to September 2012. All the patients were included irrespective of their sex and age. The written consent for the procedure was obtained from each patient.

All the concerned patients were subjected to routine investigations like $\mathrm{Hb} \%$, TLC, DLC, BT, CT, PT, SGPT, SGOT, Alkaline phosphatase, serum creatinine and serum Alphafetoprotein (AFP) was also done whenever indicated.

Radiological investigations like USG and CT scan was done to know the exact site and origin of lesions.

After taking consent for the procedure, patients were placed in a comfortable and most suitable position for aspiration. Taking all aseptic precautions, aspirations were done without any kind of anaesthesia under US guidance.

After thorough clinical examination, USG examination was performed by Sonoline 500 (Siemens) ultrasound machine having $3.5 \mathrm{MHz}$ sector (Mechanical) probe, and those found to have a mass were subjected to fine needle aspiration cytology by a 20 - $22 \mathrm{G}$ needle attached to a $20 \mathrm{~mL}$ disposable syringe for superficial masses and a $9 \mathrm{~cm} 20$ - 22 G spinal needle for deep seated masses.

Needle was passed into the proper site within the target organ and plunger is pulled to apply negative pressure. Needle was moved to and fro for a distance of about $2 \mathrm{~cm}$ for 3 - 5 times to cut tissue fragments and dislodge cells and tissue fragments to be aspirated in syringe.

Needle is withdrawn carefully. The procedure was repeated in the same site in different direction to ensure adequate representative tissue sample.

In most cases, adequacy of aspirate was assessed immediately, and aspiration was repeated if necessary. After obtaining the material, aspirates were smeared between two closely opposed slides.

In cases of cystic lesions where fluid was aspirated, smears were made after centrifugation of fluid. Prepared slides were fixed in $95 \%$ alcohol or air dried in case of MayGrunwald Giemsa stain and subsequently stained.

After staining each smear was examined under low power of microscope to get idea of cellularity of smears, and under high power and oil immersion to get individual cell details.

These cases were classified into following Categories according to the Cytological Features

- Inflammatory lesions.

- Benign lesions.

- Malignant lesions.

- Inadequate or unsatisfactory.

The Interpretation of Malignant Lesions was Chiefly Based Upon

- Cellularity.

- Dyscohesiveness of cells.

- Loss of polarity.

- Nuclear crowding.

- Nuclear cytoplasmic ratio.

- Nuclear characteristics.

- Chromatin pattern.
The inflammatory lesions were classified into acute and chronic on the basis of type of inflammatory cells present in smears.

Tubercular lesions so commonly observed in present study was identified on the presence of epithelioid granulomas and caseous necrosis.

In general, the cells in air dried smears are larger than those in wet fixed smears and the nucleoli are more easily seen in the former preparation.

These cases were then subjected for histological examination and finally the findings are correlated with that of cytological findings.

\section{Statistical Analysis}

Finally, the entire study was statistically analysed for its sensitivity, specificity and overall accuracy. Statistics was calculated in Microsoft Excel sheet-

1. Sensitivity $=$ True positive $\times 100 /$ True positive + False negative.

2. Specificity $=$ True negative $\times 100 /$ True negative + False positive.

3. Predictive value of positive test $=$ True positive $\times 100 /$ True positive + False positive

4. Predictive value of negative test $=$ True negative $\times 100 /$ False negative + True negative.

5. Diagnostic Accuracy $=$ True positive + True negative $x$ 100/ Total no. of cases.

\section{RESULTS}

In our study, we assessed 94 patients of abdomino-pelvic masses for applicability of USG guided FNAC in pre-operative diagnosis and management. Histopathological correlation and confirmation was available in 50 cases.

Out of 94 cases, 56 cases were male and 38 cases were female with a male-to-female ratio of 1.5: 1 .

Maximum number of cases in our study is in age group of (51 - 60) years followed by (41 - 50) years and (31 - 40) years (Table/Figure 1).

Most commonly involved organs in our study is liver (36.3\%) followed by gall bladder $(19.3 \%)$ and lymph nodes (15.9\%) (Table/ Figure 2).

There are more number of malignant lesions as compared to benign lesions. Benign cases are common in the age group less than 40 years and malignant cases are more common in the age group more than 40 years.

Out of total 94 cases 68 cases were malignant, 10 cases were benign and 11 cases were inflammatory and 05 smears were inadequate (Table/ Figure 3).

Malignant lesions outnumbered the benign and inflammatory lesion and comprised of total $72.4 \%$.

The majority of lesions were located in liver 34 cases followed by gall bladder 18 cases, lymph node 15 cases, GI tract and pancreas 09 cases, kidney and adrenals 08 cases, ovary 06 cases and retroperitoneum 04 cases (Table/ Figure 4).

The most common malignant lesion in the liver was metastatic adenocarcinoma 55.8\% followed by hepatocellular carcinoma (HCC) $17.6 \%$.

The incidence of malignant lesion is much more $(88.9 \%)$ than the benign lesions $(11.1 \%)$, in gall bladder lumps subjecting to FNAC (Table/ Figure 4 and 7 -12).

In the present study, metastatic lesions are the most common cause for the intra-abdominal and retroperitoneal 
lymphadenopathy followed by non-Hodgkin's lymphoma and tubercular lesion (Table/ Figure 4).

Out of total 61 cases in liver, gall bladder and gastrointestinal tract, 26 cases were subjected to histopathological examination. Cytological diagnosis were concordant with histological diagnosis in 24 cases and was discordant in 2 cases.

One inadequate smears in liver proved to be metastatic adenocarcinoma and one inflammatory lesion in gallbladder proved to be well-differentiated adenocarcinoma on histopathological examination.

Out of total 33 cases in other organs, 24 cases were subjected to histopathological examination. Cytological diagnoses were concordant with histological diagnoses in 23 cases and was discordant in 1 case. Inadequate smears in ovary proved to be papillary serous cyst adenocarcinoma.

Out of 32 cases which were diagnosed malignant on cytology, all were diagnosed as malignant on histology.

Out of 18 cases which were diagnosed as non-malignant on cytology, 15 were diagnosed as non-malignant on histology and 3 cases were diagnosed as malignant on histology giving 3 false negative results.

Sensitivity of US guided FNAC in diagnosing malignancy is $91.4 \%$, specificity $100 \%$, positive predictive value $100 \%$ and negative predictive value $83.3 \%$ (Table/ Figure 7).

\begin{tabular}{|c|c|c|}
\hline Age Group & Number of Cases & Percentage (\%) \\
\hline $0-10$ & 05 & 5.3 \\
\hline $11-20$ & 06 & 6.4 \\
\hline $21-30$ & 03 & 3.2 \\
\hline $31-40$ & 13 & 13.8 \\
\hline $41-50$ & 26 & 27.8 \\
\hline $51-60$ & 29 & 30.8 \\
\hline$>60$ & 12 & 12.7 \\
\hline Total & 94 & 100 \\
\hline \multicolumn{3}{|c|}{ Table/Figure 1. Age Incidence in Study Group } \\
\hline
\end{tabular}

\begin{tabular}{|c|c|c|}
\hline Site & No. of Cases & Percentage (\%) \\
\hline Liver & 34 & 36.3 \\
\hline Gall bladder & 18 & 19.3 \\
\hline Lymph nodes & 15 & 15.9 \\
\hline $\begin{array}{l}\text { Gastrointestinal tract } \\
\text { and pancreas }\end{array}$ & 09 & 9.5 \\
\hline Kidneys and adrenals & 08 & 8.5 \\
\hline Ovary & 06 & 6.3 \\
\hline Retroperitoneum & 04 & 4.2 \\
\hline Total & 94 & 100 \\
\hline
\end{tabular}

\begin{tabular}{|c|c|c|c|c|c|c|c|c|c|}
\hline \multirow{2}{*}{ Organ Involved } & \multicolumn{2}{|c|}{ Inflammation } & \multicolumn{2}{|c|}{ Benign } & \multicolumn{2}{|c|}{ Malignant } & \multicolumn{2}{|c|}{ Inadequate } & \multirow{2}{*}{ Total } \\
\hline & Total & $\%$ & Total & $\%$ & Total & $\%$ & Total & $\%$ & \\
\hline Liver & 03 & 3.2 & 01 & 1.1 & 28 & 29.8 & 02 & 2.1 & 34 \\
\hline Gall Bladder & 02 & 2.1 & 00 & - & 16 & 17.0 & 00 & - & 18 \\
\hline Lymph Node & 02 & 2.1 & 02 & 2.1 & 10 & 10.7 & 01 & 1.1 & 15 \\
\hline $\begin{array}{c}\text { GI Tract } \\
\text { and Pancreas }\end{array}$ & 04 & 4.3 & 01 & 1.1 & 03 & 3.2 & 01 & 1.1 & 09 \\
\hline Kidney and Adrenal & 00 & - & 02 & 2.1 & 06 & 6.5 & 00 & - & 08 \\
\hline Ovary & 00 & - & 02 & 2.1 & 03 & 3.1 & 01 & 1.1 & 06 \\
\hline Retroperitoneum & 00 & - & 02 & 2.1 & 02 & 2.1 & 00 & - & 04 \\
\hline Total & 11 & 11.7 & 10 & 10.6 & 68 & 72.4 & 05 & 5.3 & 94 \\
\hline
\end{tabular}

\begin{tabular}{|c|c|c|c|c|c|c|}
\hline Organ & Benign No. of Cases Per & entag & & Malignant No. of Cases Pe & ercen & tage \\
\hline & & & & Metastatic Adenocarcinoma & & 21.34 \\
\hline & & & & Hepatocellular Carcinoma & 06 & 6.74 \\
\hline Liver & Abscess & 03 & 3.31 & Metastatic Squamous & 01 & 1.12 \\
\hline & Adenoma & & & Metastatic Neuroendocrine & 01 & 1.12 \\
\hline & & & & Lymphoma & 01 & 1.12 \\
\hline Gall Bladder & Inflammatory lesions & 02 & 224 & Adenocarcinoma & 15 & 16.8 \\
\hline & Inflammatory lesions & 02 & 2.24 & Poorly Differentiated & 01 & \\
\hline Jymnh Node & Reactive Hyperplasia & 02 & 2.24 & NHL & 04 & 4.5 \\
\hline Lympn Node & Tubercular & 02 & 2.24 & Metastatic & 06 & 6.7 \\
\hline & Tubercular and Inflammatory & 04 & 4.5 & & & \\
\hline GI Tract and Pancreas & Solid Papillary and Cystic & & & Adenocarcinoma & 03 & 3.37 \\
\hline & Neoplasm of Pancreas & 01 & 1.12 & & & \\
\hline Renal/Adrenal & Renal Oncocytoma & 01 & 1.12 & Renal Cell Carcinoma & 04 & 4.5 \\
\hline Renal/ Aarenal & Pheochromocytoma & 01 & 1.12 & Wilms' Tumour & 02 & 2.24 \\
\hline Oyכry & Serous Cyst Adenoma & 01 & 1.12 & Serous Cyst Adenocarcinoma & 02 & 2.24 \\
\hline Uvary & Dermoid Cyst Ovary & 01 & 1.12 & Krukenberg Tumour & 01 & 1.12 \\
\hline Retroneritoneum & Benion & 02 & 224 & Round Cell Tumour & 01 & 1.12 \\
\hline Ketroperntoneum & Benign & 02 & 2.24 & Malignant Fibrous Histiocytoma & a 01 & 1.12 \\
\hline Total & 2123.5 & & & 6875.5 & & \\
\hline & Table/Figure 4. Cytologi & $i a c$ & sis $\mathrm{C}$ & tra-Abdomino-Pelvic Lesions & & \\
\hline
\end{tabular}




\begin{tabular}{|c|c|c|c|}
\hline Site & $\begin{array}{c}\text { Zawar MP } \\
\text { et al 2007 }\end{array}$ & $\begin{array}{c}\text { Sainath et al } \\
\mathbf{2 0 1 1}\end{array}$ & $\begin{array}{c}\text { Our Study } \\
\text { (\%) }\end{array}$ \\
\hline Liver & 45 & 38 & 36.3 \\
\hline Gall Bladder & 2.5 & 2.6 & 19.3 \\
\hline Lymph Nodes & 2.5 & 7.9 & 15.9 \\
\hline $\begin{array}{c}\text { Gastrointestinal } \\
\text { Tract and Pancreas }\end{array}$ & 25 & 2.5 & 9.5 \\
\hline $\begin{array}{c}\text { Kidneys and } \\
\text { Adrenals }\end{array}$ & 20 & 5.2 & 8.5 \\
\hline Ovary & - & 21.1 & 6.3 \\
\hline Retroperitoneum & - & 3.9 & 4.2 \\
\hline Table/rigure 5. Organ Distribution
\end{tabular}

Table/ Figure 5. Organ Distribution of Intra-Abdominal Malignancy-Comparative Analysis

\begin{tabular}{|c|c|c|c|c|}
\hline Study & $\begin{array}{c}\text { No. of } \\
\text { FNACs }\end{array}$ & Sensitivity & Specificity & $\begin{array}{c}\text { Diagnostic } \\
\text { Accuracy }\end{array}$ \\
\hline $\begin{array}{c}\text { Aftab A Khan } \\
\text { et al 1995 }\end{array}$ & 50 & 94 & 100 & 94 \\
\hline $\begin{array}{c}\text { Shamshad } \\
\text { et al 2006 }\end{array}$ & 200 & 94.1 & 100 & 95.7 \\
\hline $\begin{array}{c}\text { Zawar MP } \\
\text { et al 2007 }\end{array}$ & 40 & - & - & 90 \\
\hline $\begin{array}{c}\text { Sainath } \\
\text { et al 2011 }\end{array}$ & 245 & 94.1 & 100 & 96.5 \\
\hline $\begin{array}{c}\text { Hemlatha } \\
\text { AL 2013 }\end{array}$ & 90 & 94 & 100 & 96.3 \\
\hline Our Study & 94 & 91.4 & 100 & 94 \\
\hline \multicolumn{7}{|c|}{ Table/ Figure 6. Statistical Results Comparative Analysis } \\
\hline
\end{tabular}

\begin{tabular}{|c|c|c|c|}
\hline \multirow{2}{*}{ Cytology } & \multicolumn{2}{|c|}{ Histology } & \multirow{2}{*}{ Total } \\
\cline { 2 - 3 } & Malignant & Non-Malignant & \\
\hline Malignant & 32 & 0 & 32 \\
\hline Non-malignant & 03 & 15 & 18 \\
\hline Total (50) & $\mathbf{3 5}$ & $\mathbf{1 5}$ & $\mathbf{5 0}$ \\
\hline Table/ Figure 7. Correlation of Cytological and \\
Histological Diagnosis as a Predictor of Malignancy \\
\hline
\end{tabular}

Out of 32 cases which were diagnosed malignant on cytology, all the 32 cases were diagnosed as malignant on histology giving no false positive result.

Out of 18 cases which were diagnosed as non-malignant on cytology, 15 were diagnosed as non-malignant on histology and 3 cases were diagnosed as malignant on histology giving 3 false negative result.

Sensitivity of US guided FNAC in diagnosing malignancy is $91.4 \%$, specificity $100 \%$, positive predictive value $100 \%$, negative predictive value in $83.3 \%$ and diagnostic accuracy is $94 \%$.

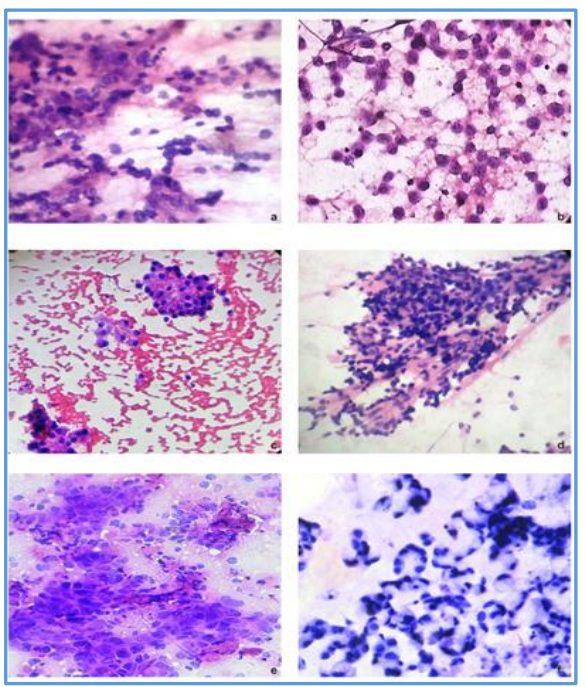

Table/ Figure 8

(a) Microphotograph of Aspirate from Liver showing Cells with Prominent Nucleoli and Intranuclear Inclusions suggestive of HCC (H and E, X 400)

(b) Microphotograph showing Malignant Cells with Neuroendocrine Differentiation-Metastatic Neuroendocrine in Liver (H and $E, X$ 400)

(c) Microphotograph showing PheochromocytomaAdrenal (H and $E, X$ 400)

(d) Microphotograph showing Solid and Cystic Papillary Epithelial Neoplasm of Pancreas (H and E, X 400)

(e) Microphotograph showing Adenocarcinoma Ovary (H and $E, X 400$ )

(f) Microphotograph showing Signet Ring Cell as well as Acini Formation in Krukenberg Tumour Ovary ( $H$ and $E, X$ 400)

\section{DISCUSSION}

Fine needle aspiration cytology is an interpretative art with histopathology. The present study is formulated to assess the value of US guided FNAC in the diagnosis of intra-abdominal lumps and to correlate them histologically.

Differentiation between benign and malignant disease is at times vital to avoid an exploratory laparotomy, especially in advanced unresectable malignant cases.

Ultrasound guided FNAC is a rapid, accurate, economical and a safe diagnostic procedure that can be used in various neoplastic and non-neoplastic diseases.

As diagnosis is rapidly available on FNAC, the appropriate medical or surgical therapies can be started earlier, thus avoiding unnecessary, expensive and often invasive diagnostic procedures. ${ }^{8}$

In our study, 94 cases of intra-abdominal and pelvic lumps were subjected to US guided FNAC. US revealed that mass lesions were located in liver $36.3 \%$, gall bladder $19.3 \%$, lymph node $15.9 \%$, GI tract and pancreas $9.5 \%$, kidney and adrenals $8.5 \%$, ovary $6.3 \%$ and retroperitoneum $4.2 \%$ as shown in Table/ Figure 2.

In our study FNAC gave definite conclusive diagnosis in $94 \%$ of cases, which is higher and comparable to other studies done elsewhere in the past.

In our study we found a diagnostic yield of $94.7 \%$, which is higher than the study done by Tasleem et al in 2006 who found a diagnostic yield of $90.5 \%$ cases and Nautiyal S et al in 2004 who found a diagnostic yield of $64.81 \%$ with direct aspiration of the palpable lumps and a diagnostic yield of 93.06\% with USG guided FNAC, which was done for both palpable and non-palpable lesions. ${ }^{9,1}$

The age incidence in our study ranged from 2 years to 78 years with a majority of the cases being in the age group of 51 - 60 years (Table/ Figure 1), which was comparable to the results which were obtained by Zawar MP et al and Tasleem et al.4,9

The male-to-female ratio of 3: 2 showing male preponderance was in accordance with the observations which were made in the studies by Zawar MP et al, Govind Krishna et al, Aftab A Khan et al and Tasleem et al showed a male preponderance. $4,6,10,9$

In our study, Liver was the commonest sites for FNAC followed by gall bladder as shown in which it is comparable to the studies done by Tasleem et al and Sainath et al, Sheikh et al and Zawar MP et al (Table/ Figure 5). 
However, in Sainath et al study, ovary followed liver as compared to gall bladder in our study. $9,2,11,4$

In our study, it was observed that a majority were malignant lesions which comprised of $72.40 \%$ lesions and the remaining 22.3\% were benign and non-neoplastic lesions and $5.3 \%$ were being inconclusive smears (Table/ Figure 3).

This was higher in comparison to study of smith et al, in which $66 \%$ were malignant lesion and $34 \%$ were benign and non-neoplastic and in our study number of malignant lesions is lower in comparison to study by Tasleem et al study in which $78.3 \%$ were malignant and $12.26 \%$ were benign and non-neoplastic lesions. ${ }^{12,9}$

In our study, adenocarcinomas were the most common malignant cell type (38.2\%) followed by hepatocellular carcinoma $6.38 \%$ and renal cell carcinoma $4.2 \%$ (Table/ Figure 4 and 7 - 12). This was in accordance with the observations which were made by Sainath et al and Shamshad et al.2,13

In our study in the liver, the most common malignant lesion was metastatic adenocarcinoma followed by HCC which is comparable to the study of Tasleem et al, Aftab et al, Shamshad et al and most of western literature, in which the most common hepatic malignancy was metastatic carcinoma. $9,10,13,14,15,16$

The observations of our study were not similar to those of some other Indian studies, where hepatocellular carcinoma constituted the most common hepatic malignancy. ${ }^{2,4}$

In our study we observed $5.3 \%$ inconclusive smears, which was lower than the observations made by Tasleem et al, Shamshad et al and Aftab A Khan et al who observed $9.43 \%, 6.5 \%$ and $6 \%$ unsatisfactory smears, $9,13,10$ which could be attributed to many reasons and depends on many factors like location, size, accessibility, vascularity, necrotic component, consistency, nature and histologic type of the lesion. In the present study, liver constituted the major site for the malignant lesions as observed by Stewart, Zawar MP and Sainath et al and Nautiyal (Table/ Figure 5).3,4,2,1

The second most common site was gall bladder in our study which is comparable to Tasleem et al study, ${ }^{9}$ while Sainath, Zawar MP and Biradar et al have ovary, kidney and large bowel respectively as the second most common site. ${ }^{2,4,17}$

A vast amount of literature supports the safety of FNAC with little or no complication. Although, few studies have reported complications like mild local pain, bleeding and tumour seeding of the needle tract.

In present study, we did not find any complication except mild pain at the time of needle puncture. Including those of the present study, there was no report on complications as a result of FNAC in the previous studies. ${ }^{2}$

In our study sensitivity was $91.4 \%$, which was comparable to that of most of the studies sensitivity ranging from $71.4 \%$ to $96.3 \%$. All the studies observed $100 \%$ specificity, as was found in our study also. The present study found a diagnostic accuracy of $94 \%$, which was comparable to that of most of the studies which found a diagnostic accuracy ranging from $83.9 \%$ to $100 \%$ (Table/ Figure 6).

\section{CONCLUSION}

FNA is a safe economical and simple OPD procedure and can be used as an important diagnostic tool for the pre-operative diagnosis and management of any abdominal lumps. Use of imaging techniques helps in proper localisation of lesions and also improved adequacy of sample.
It is a safe, useful method in differentiating between inflammatory, benign and malignant lesions with a high diagnostic accuracy for the diagnosis of malignant lesions.

\section{REFERENCES}

[1] Nautiyal S, Mishra RK, Sharma SP. Routine and ultrasound guided FNAC of intra abdominal lumps-a comparative study. J Cytol 2004;21(3):129-32.

[2] Sidhalingreddy, Andola SK. Fine needle aspiration cytology of intra-abdominal lesions. Journal of Clinical and Diagnostic Research 2011;5(3):551-8.

[3] Stewart CJ, Coldewey J, Stewart IS. Comparison of fine needle aspiration cytology and needle core biopsy in the diagnosis of radiologically detected abdominal lesions. J Clin Pathol 2002;55(2):93-7.

[4] Zawar MP, Bolde S, Shete SS. Correlative study of fine needle aspiration cytology and histology in intraabdominal lumps. SMJ 2007;4.

[5] Ennis MG, MacErlean DP. Percutaneous aspiration biopsy of abdomen and retroperitoneum. Clin Radiol 1980;31(5):611-6.

[6] Krishna SR, Ananthakrishnan N, Narasimhan R, et al. Accuracy of fine needle aspiration cytology of abdominal masses without radiological guidance. Indian J Pathol Microbiol 1993;36(4):442-52.

[7] Gazelle GS, Haaga JR. Guided percutaneous biopsy of intraabdominal lesions. AJR Am J Roentgenol 1989;153(5):929-35.

[8] Langlois S, Le P. Imaging methods for guidance of aspiration cytology. In: Orell SR, Sterrett GF, Whitaker D. Fine needle aspiration cytology. $4^{\text {th }}$ edn. New Delhi: Churchill Livingstone, 2005:31-40.

[9] Reyaz TA, Summyia F, Isma N, et al. USG guided fine needle aspiration cytology of intra-abdominal and pelvic masses in Kashmir: a study at tertiary care hospital. International Journal of Medical Research \& Health Sciences 2016;5(4):169-75.

[10] Khan AA, Jan GM, Wani NA. Fine needle aspiration of intra-abdominal masses for cytodiagnosis. J Indian Med Assoc 1996;94(5):167-8, 194.

[11] Sheikh M, Sawahney S, Dey P, et al. Deep-seated thoracic and abdominal masses: usefulness of ultrasound and computed tomography guidance in fine needle aspiration cytology diagnosis. Australas Radiol 2000;44(2):155-60.

[12] Smith C, Butler JA. Efficacy of directed percutaneous fine needle aspiration cytology in the diagnosis of intra-abdominal masses. Arch Surg 1988;123(7):8204.

[13] Ahmed SS, Akhtar K, Akhtar SS, et al. Ultrasound guided fine needle aspiration biopsy of abdominal masses. JK Science 2006;8(4):200-4.

[14] Orell SR, Sterrett GF, Whitaker D. Fine needle aspiration cytology. $4^{\text {th }}$ edn. Churchill Livingstone Elsevier, 2005:440-1.

[15] Rosai J, Desmet VJ, Nelson GO. Rosai and Ackerman's surgical pathology. $9^{\text {th }}$ ed. Mosby, 2005.

[16] Centeno BA. Pathology of liver metastases. Cancer Control 2006;13(1):13-26.

[17] Biradar VB. A study of fine needle aspiration cytology in abdominal lump (dissertation). Gulbarga: University of Gulbarga, 1994. 